\title{
PREPARATION, CHARACTERIZATION AND UTILIZATION OF A NOVEL TRIFLUOROACETIC ACID SUPPORTED STARCH/GRAPHENE OXIDE GREEN NANOCOMPOSITE FOR EFFICIENT SYNTHESIS OF 2,4,5-
} TRISUBSTITUTED IMIDAZOLES

\author{
ESMAEL ROSTAMI and MARYAM SADAT GHORAYSHI NEJAD \\ Department of Chemistry, Payame Noor University, \\ PO BOX 19395-3697 Tehran, Iran \\ ๔orresponding author: E. Rostami, e.rostami@pnu.ac.ir
}

Received June 16, 2021

\begin{abstract}
This study reports on the production, characterization, and application of a novel starch/graphene oxide nanocomposite for rapid synthesis of 2,4,5-trisubstituted imidazoles. To this end, graphene oxide was first functionalized by 1,8 diamino-3,5-dioxaoctane under appropriate conditions. Starch, functionalized graphene oxide, and 3-aminopyridine nanocomposite were then prepared from the reaction of starch with graphene oxide functionalized with 1,8-diamino3,5-dioxaoctane in the presence of hexamethylene diisocyanate (HDMI) as a binding agent and 3-aminopyridine. Then, trifluoroacetic acid was added, giving rise to an acid-supported starch and graphene oxide nanocomposite. To examine the efficiency of the nanocomposite, 2,4,5-trisubstituted imidazoles were efficiently synthesized in the presence of the nanocomposite using benzil, aryl aldehyde, and ammonium acetate under solvent-free condition within a short reaction time. The moderate conditions, fast reaction rates, ease of purification, solvent-free condition, use of a green catalyst (nanocomposite), and environmental friendliness are among the advantages of the proposed synthesis method. The recoverability and durability of the catalyst were confirmed after five runs with no significant loss of activity. Thus, this research presents a novel nanocomposite based on starch and graphene oxide with superior properties.
\end{abstract}

Keywords: starch, graphene oxide, nanocomposite, green catalyst, 2,4,5-trisubstituted imidazole

\section{INTRODUCTION}

Imidazole is a five-membered aromatic heterocycle with two nitrogen atoms. The core structure of imidazole occurs in many organic compounds including natural products, ${ }^{1}$ biologically active compounds, ${ }^{2}$ pharmaceuticals ${ }^{3}$ and synthetic products. ${ }^{4}$ This heterocyclic ring could be also found in vitamins, ${ }^{5}$ antifungal compounds, ${ }^{6}$ herbicides, ${ }^{7}$ plant growth regulators, ${ }^{8}$ and anti-inflammatory products. ${ }^{9}$ Several drugs, such as Omeprazole, Olmesartan, and Trifenageral, also include imidazole in their structures. ${ }^{10}$

Multicomponent reactions (MCRs) are capable of significant structural variations, including the use of diketones and amine structures. ${ }^{11}$ Green chemistry and multicomponent reactions are intended to develop methods under more favorable states (e.g. solvent-free and environmentally benign conditions, as well as using inexpensive catalysts) to design efficient reactions with higher yields and simple workup, while resulting in no by-products. These procedures provide rapid and simple access to a series of molecules with favorable properties, especially biological activities. ${ }^{12,13}$

The synthesis of 2,4,5-trisubstituted imidazoles can be achieved from the reaction of benzil, aromatic aldehydes and ammonium acetate via multicomponent reactions through a series of catalytic systems, including pyridine-2carboxylic acid as an organocatalyst, ${ }^{14}$ claysupported heteropolyacid, ${ }^{15}$ magnetic $\mathrm{Fe}_{3} \mathrm{O}_{4}{ }^{16}$ $\mathrm{MgAl}_{2} \mathrm{O}_{4} \quad$ nanoparticles, ${ }^{17} \quad \mathrm{NiCl}_{2} \cdot 6 \mathrm{H}_{2} \mathrm{O},{ }^{18}$ $\mathrm{Pb}(\mathrm{OAc})_{2},{ }^{19}$ vanadate sulfuric acid nanorods, ${ }^{20}$ $\mathrm{ZrCl}_{4},{ }^{21}$ periodic mesoporous organosilica supported benzotriazolium ionic liquids, ${ }^{22}$ amino glucose-functionalized silica-coated $\mathrm{NiFe}_{2} \mathrm{O}_{4}$ nanoparticles ${ }^{23}$ and $\mathrm{Ce}\left(\mathrm{NH}_{4}\right)_{2}\left(\mathrm{NO}_{3}\right)_{6} \cdot{ }^{24}$ However, 
these reactions suffer from several drawbacks, including long reaction times, unwanted byproducts, and the use of toxic and expensive catalysts. In this context, the studies have been focused on finding new synthetic routes for the preparation of 2,4,5-trisubstituted imidazoles using cost-effective and non-toxic catalysts.

Recently, polymer-functionalized catalysts have gained great attention due to their superiority over conventional catalysts, including their ease of separation and work-up, low cost, compatibility with other materials, facile functionalization, and non-toxicity. ${ }^{25-27}$ Starch is a natural, non-toxic, environmentally friendly, and biocompatible compound with promising potential in the preparation of composites. ${ }^{28-30} \mathrm{In}$ view of this, starch has been widely used in numerous catalytic systems as polymer support, thus, it could be a good candidate in green and sustainable chemistry. ${ }^{31-33}$ The hydroxyl groups in the structure of starch offer proper functional sites for surface modification through a broad range of reactions. ${ }^{34-36}$ Chemically modified starch and its nanocomposites have been widely employed in various applications, such as catalysts, ${ }^{37}$ water treatments, ${ }^{38,39}$ drug delivery, ${ }^{40}$ and biological applications. ${ }^{41}$ Recently, several studies have addressed starch-graphene oxide nanocomposites as a biocompatible and safe candidate for diverse applications, including catalytic processes ${ }^{42}$ water treatment, ${ }^{43}$ bio-based materials, ${ }^{44}$ food industry, ${ }^{45}$ packaging, ${ }^{46}$ membranes ${ }^{47}$ and electronics. ${ }^{48}$ Novel starch-graphene oxide nanocomposites can be designed by the use of doped and functionalized graphene and graphene oxide as fillers, in the presence of appropriate organic reactions. ${ }^{49-51}$

In this research, graphene oxide was functionalized with 1,8-diamino-3,5-dioxaoctane via amide formation. Then, the starch and aminefunctionalized graphene oxide nanocomposite was prepared using hexamethylene diisocyanate as a binding agent and trifluoroacetic acid (TFA) as a supported acid catalyst. Finally, 2,4,5trisubstituted imidazole was efficiently synthesized using the developed nanocomposite under solvent-free conditions.

\section{EXPERIMENTAL}

\section{Materials and equipment}

All the chemicals were acquired from Merck and other well-reputed companies. The obtained products were identified by comparing their melting points with the reported values. Melting points were recorded by a thermal scientific apparatus using an open capillary tube. Thin-layer chromatography (TLC) was also performed on Merck $\mathrm{F}_{254}$ alumina plates. ${ }^{1} \mathrm{HNMR}$ and ${ }^{13} \mathrm{CNMR}$ spectra were recorded by Bruker Avance DRX $400 \mathrm{MHz}$ and Bruker Avance DPX $300 \mathrm{MHz}$ spectrometers. Mass spectra were measured by an Agilent model 5975c-inert MSD, consisting of a Triple-Axis Detector mass spectrometer. Thermogravimetric analysis (TGA) was conducted using an SDT Q600 V20.9 Build 20 apparatus. Fourier transform infrared (FT-IR) spectra were obtained by a JASCO, FT/IR-6300 FT-IR spectrometer utilizing $\mathrm{KBr}$ pellets. The elemental concentrations on the sample surface were tested using a semi-quantitative EDX (Tescan Mira III, Czech) apparatus. The morphology of the samples was studied using a TE-SCAN fieldemission scanning electron microscope (FESEM). A Bruker AXSD 8 Advance X-ray diffractometer was also utilized to record X-ray diffraction (XRD) patterns of powders using monochromatic $\mathrm{CuK} \alpha$, radiation $(\lambda=$ $\left.1.5406 \mathrm{~A}^{\circ}\right)$.

Preparation of graphene oxide functionalized with 1,8-diamino-3,5-dioxaoctane (GO@ Amine)

The modified Hummer's method was utilized for the synthesis of graphene oxide (GO) from graphite. $^{52,53}$ GO $(1.00 \mathrm{~g})$ was added to dimethylacetamide $(30 \mathrm{~mL})$ solvent and sonicated in an ultrasonic bath for $30 \mathrm{~min}$ to obtain a homogeneous emulsion. Then, 1,8-diamino-3,5-dioxaoctane (5 mmol, $\quad 0.73 \mathrm{~mL}), \quad N, N^{\prime}$-dicyclohexylcarbodiimide (DCC, $3 \mathrm{mmol}, 0.62 \mathrm{~g}$ ), and triethylamine $(6 \mathrm{mmol}$, $0.84 \mathrm{~mL}$ ) were added at room temperature and stirring was continued for further $48 \mathrm{~h}$. The resulting mixture was diluted with dimethyl sulfoxide (DMSO, $20 \mathrm{~mL}$ ) and water $(5 \mathrm{~mL})$, followed by heating and hot filtration. The precipitate was washed with hot ethanol $(20 \mathrm{~mL})$ and water $(20 \mathrm{~mL})$. For further purification, ethanol was added to the precipitated crude products, which were sonicated and centrifuged, followed by vacuum-drying at $60{ }^{\circ} \mathrm{C}$ to obtain graphene oxide functionalized with 1,8-diamino-3,5-dioxaoctane (GO@Amine) (Scheme 1). FTIR (KBr): $v_{\max }=615$, $1124,1460,1630,1691,2923,3031,3437 \mathrm{~cm}^{-1}$.

Preparation of starch/graphene oxide functionalized with 1,8-diamino-3,5-dioxaoctane and 3-aminopyridine nanocomposite (Starch@GOPy)

Starch $(1.50 \mathrm{~g})$ was added to dimethylformamide (DMF, $15 \mathrm{~mL}$ ) and the mixture was heated at $80^{\circ} \mathrm{C}$ for $4 \mathrm{~h}$. On the other hand, GO@Amine $(0.30 \mathrm{~g})$ was added to dimethylacetamide $(15 \mathrm{~mL})$ and the mixture was sonicated in an ultrasonic bath to obtain a dispersed medium. Then, the GO@ Amine solution was mixed with the starch solution and agitated for $20 \mathrm{~min}$ at $60{ }^{\circ} \mathrm{C}$. Afterward, hexamethylene diisocyanate $(0.20$ $\mathrm{mL})$ and triethylamine $(0.30 \mathrm{~mL})$ were added and the reaction continued for another $5 \mathrm{~h}$, followed by the 
addition of 3-aminopyridine ( $4 \mathrm{mmol}, 0.38 \mathrm{~g}$ ) at $80^{\circ} \mathrm{C}$. The stirring was continued for $10 \mathrm{~h}$ at $80{ }^{\circ} \mathrm{C}$. After the addition of methanol $(5 \mathrm{~mL})$, the reaction was continued for $2 \mathrm{~h}$ at room temperature. Finally, deionized water was added $(10 \mathrm{~mL})$ and the mixture was centrifuged and washed with ethanol to reach the Starch@GO-Py nanocomposite (Scheme 2). FTIR $(\mathrm{KBr}): v_{\max }=577,1015,1153,1623,2929,3370 \mathrm{~cm}^{-1}$.

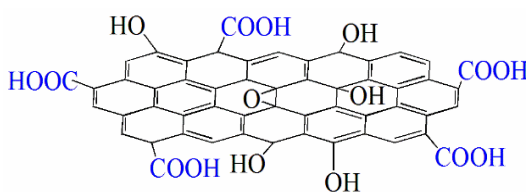

Graphene Oxide (GO)

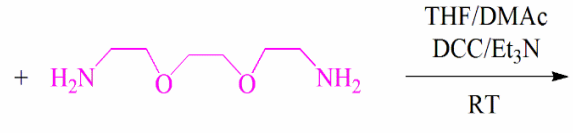

1,8-diaza-3,5-dioxaoctane

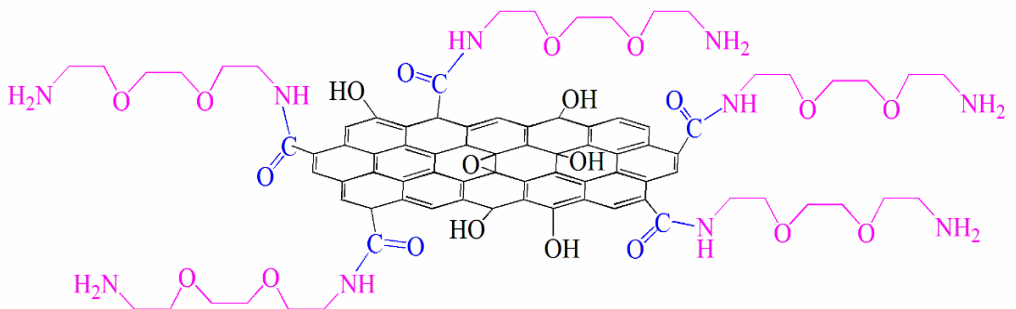

GO@Amine

Scheme 1: Synthesis of graphene oxide functionalized with 1,8-diamino-3,5-dioxaoctane
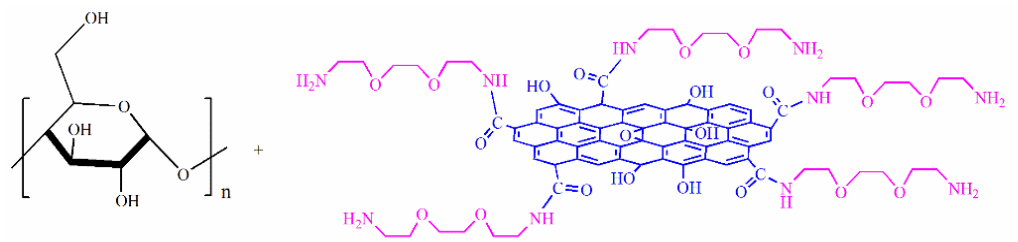

1. DMF/Et ${ }_{3} \mathrm{~N}$

2. Hexamethylene diisocyanate

3. 3-Aminopyridine

Heat

(GO@Amine)

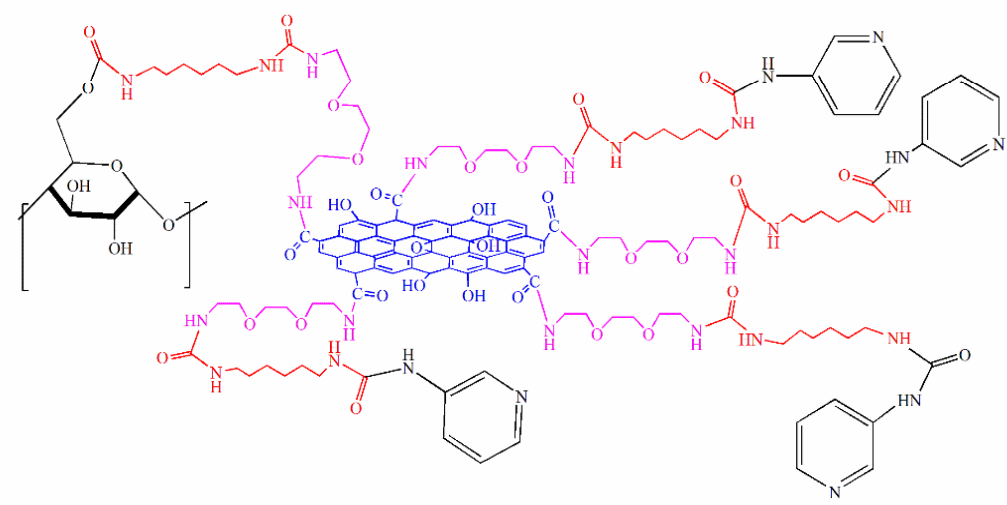

Starch@GO-Py

Scheme 2: Synthesis of Starch@GO-Py nanocomposite 


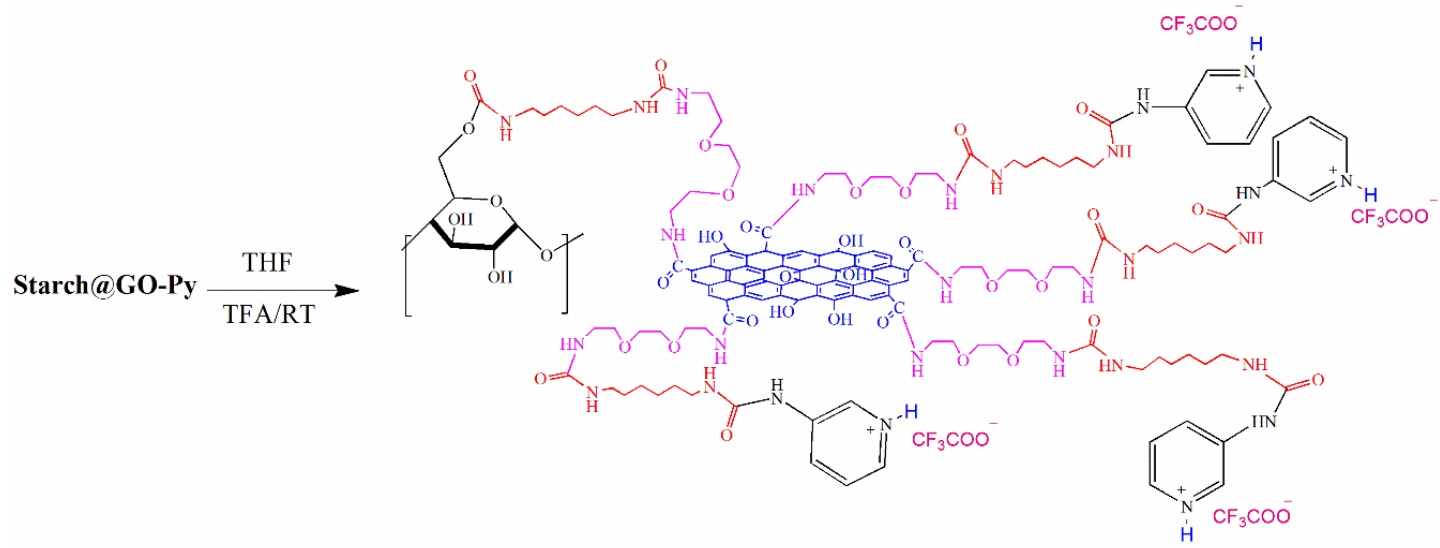

Starch@GO-PyH.CF 3 COO

Scheme 3: Synthesis of Starch@ GO-PyH.CF 3 COO nanocomposite

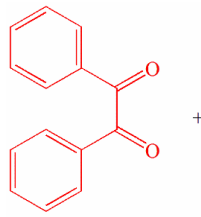

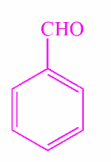

2a
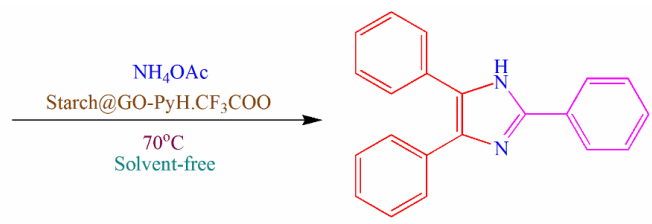

3a

Scheme 4: The Model reaction for the Synthesis of 2,4,5-trisubstituted imidazoles

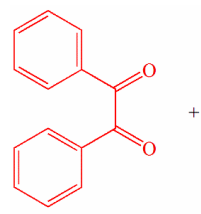

1

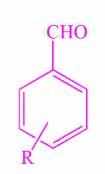

2
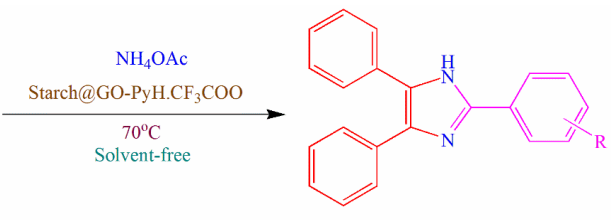

3

$\mathrm{R}=\mathrm{H}, \mathrm{Cl}, \mathrm{Br}, \mathrm{F}, \mathrm{CH}_{3}, \mathrm{NO}_{2}, \mathrm{~N}\left(\mathrm{CH}_{3}\right)_{2}$,

$\mathrm{OCH}_{3}, \mathrm{OH}, 4-\mathrm{NO}_{2}-\mathrm{Ph}-\mathrm{CH}_{2} \mathrm{O}-\mathrm{Ph}$

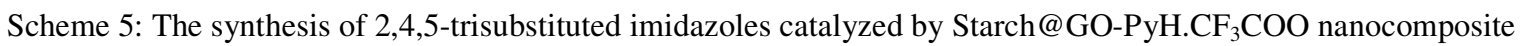

Preparation of starch/graphene oxide functionalized with 1,8-diamino-3,5-dioxaoctane and 3-aminopyridine TFA supported nanocomposite (Starch@GO-PyH.CF $\mathbf{3}$ COO)

Starch@GO-py nanocomposite (1.00 g) was added to THF $(15 \mathrm{~mL})$ and the mixture was sonicated for 30 min to attain a homogeneous colloidal solution. After cooling down to $40{ }^{\circ} \mathrm{C}$ and the addition of trifluoroacetic acid $(0.50 \mathrm{~mL})$, the stirring was continued overnight. Finally, the crude mixture was centrifuged and washed with dry chloroform and dried under reduced pressure at $60{ }^{\circ} \mathrm{C}$, to obtain Starch@GO-PyH.CF 3 COO nanocomposite (Scheme
3). FTIR (KBr): $v_{\max }=575,1018,1153,1624,2928$, $3398 \mathrm{~cm}^{-1}$.

General procedure for the synthesis of 2,4,5trisubstituted imidazoles

Benzil (1 mmol, $0.21 \mathrm{~g})$, ammonium acetate $(2.5$ mmol, $0.19 \mathrm{~g}$ ), and starch@GO-PyH- $\mathrm{CF}_{3} \mathrm{COO}$ nanocomposite $(0.02 \mathrm{~g})$ were added to aldehyde (1 mmol) and the homogenized mixture was placed in an oil bath at $70{ }^{\circ} \mathrm{C}$. After termination of the reaction (detected by TLC), ethanol $(10 \mathrm{~mL})$ was added and the solution was heated and filtered hot (Schemes 4 and 5). Afterward, the products crystallized upon cooling. The nanocomposites on the filter paper were washed with 
ethanol several times and dried. They were then reused in the reaction (entry $1, \mathbf{4 a}$ in Table 2 ). This process was repeated 4 times to examine the durability and recoverability of the nanocomposite, as well as its reactivity.

Selected spectral data of the synthesized $2,4,5$ trisubstituted imidazoles 2,4,5-triphenyl-1H-imidazole (3a)

${ }^{1} \mathrm{H}$ NMR (300 MHz, DMSO-d $\left.{ }_{6}\right) \delta: 7.29-7.63(\mathrm{~m}$, 13H), 8.17-8.20 (m, 2H), 13.13 (s, 1H) ppm; ${ }^{13} \mathrm{C}$ NMR $\left(75 \mathrm{MHz}, \mathrm{DMSO}-\mathrm{d}_{6}\right) \quad \delta: 172.80,146.10,130.92$, $129.66,129.17,128.90,128.72,128.30,127.61$, $126.09,125.75 \mathrm{ppm}$.

\section{2-(3-nitrophenyl)-4,5-diphenyl-1H-imidazole (3j)}

${ }^{1} \mathrm{H}$ NMR (300 MHz, DMSO-d $\left.{ }_{6}\right) \delta: 7.31-7.43(\mathrm{~m}$, $6 \mathrm{H}) .7 .56-7.58(\mathrm{~m}, 4 \mathrm{H}), 7.73-7.78(\mathrm{~m}, 1 \mathrm{H}), 8.20(\mathrm{~d}, J=$ $8.2 \mathrm{~Hz}, 1 \mathrm{H}), 8.53(\mathrm{~d}, J=7.9 \mathrm{~Hz}, 1 \mathrm{H}), 8.98(\mathrm{~s}, 1 \mathrm{H})$ ppm; ${ }^{13} \mathrm{C}$ NMR (75 MHz, DMSO-d 6 ) $\delta: 172.70$, $148.79,143.86,132.32,131.61,130.78,128.93$, $128.57,128.27,127.86,126.26,122.98,119.88 \mathrm{ppm}$.

\section{2-(4(4-nitro-benzyloxy) phenyl)-4,5-diphenyl-1H- imidazole (3l)}

${ }^{1} \mathrm{H}$ NMR (400 MHz, DMSO-d $\left.\mathrm{d}_{6}\right) \delta: 5.35(\mathrm{~s}, 2 \mathrm{H})$, 7.14-7.16 (m, 2H), 7.30-7.51 (m, 10H), $7.76(\mathrm{t}, J=3$ $\mathrm{Hz}, 2 \mathrm{H}), 8.02-8.04(\mathrm{~m}, 2 \mathrm{H}), 8.27-8.29$ (m, 2H), 12.53 (s, 1H) ppm; ${ }^{13} \mathrm{C}$ NMR $(100 \mathrm{MHz}$, DMSO-d 6 ) $\delta$ : $158.53,147.45,145.98,145.31,136.80,132.01$, $128.83,128.67,127.40,127.25,124.21,124.04$, 122.42, 115.45, 68.74 ppm; MS (EI) m/z $447[\mathrm{M}]^{+}$.

\section{RESULTS AND DISCUSSION}

Graphene oxide (GO) was prepared using the modified Hummer's method. ${ }^{52,53}$ As appeared in the FTIR spectrum of the graphene oxide (GO) (Fig. 1a), the $\mathrm{C}-\mathrm{O}$ vibration bands can be observed at $1177 \mathrm{~cm}^{-1}$. The $\mathrm{C}=\mathrm{O}$ group vibration emerged at $1720 \mathrm{~cm}^{-1}$, while the vibration bands at $3419 \mathrm{~cm}^{-1}$ can be assigned to $\mathrm{OH}$ stretching vibrations. The powder XRD pattern demonstrated the diffraction peak at $2 \Theta=11^{\circ}$ (Fig. 2a).

Subsequently, GO (1.00 g) was functionalized using 1,8-diamino-3,5-dioxaoctane to obtain amine-functionalized graphene oxide (GO@Amine, Scheme 1). The FTIR spectrum of GO@Amine can be found in Figure 1b. The C-O vibration bands can be observed at $1124 \mathrm{~cm}^{-1}$. The $\mathrm{OH}$ and $\mathrm{NH}$ stretching vibration bands emerged at $3437 \mathrm{~cm}^{-1}$. The XRD pattern indicated diffraction peaks in the range of $2 \theta=20-30^{\circ}$ (Fig. 2b). Compared to GO (Fig. 2a and b), the structure of functionalized graphene oxide exhibited some alterations.

Figure 3a shows the FESEM micrograph of GO@Amine. As can be seen, the sample possessed a smooth structure with nanosized components (smaller than $50 \mathrm{~nm}$ ). The energy dispersive spectroscopy (EDS) of GO@Amine (Fig. 4) confirmed the presence of $\mathrm{C}, \mathrm{N}$, and $\mathrm{O}$ elements.

In the next step, starch, GO@Amine, and 3aminopyridine (Starch@GO-Py) nanocomposite were prepared using hexamethylene diisocyanate (HDMI), for covalent binding, in DMF solvent in the presence of triethylamine under heating conditions (Schemes 2 and 3). Then, 3aminopyridine was added to complete the reaction. Ultimately, methanol was added to remove unreacted isocyanate groups, followed by adding water to reach the Starch@GO-Py nanocomposite.

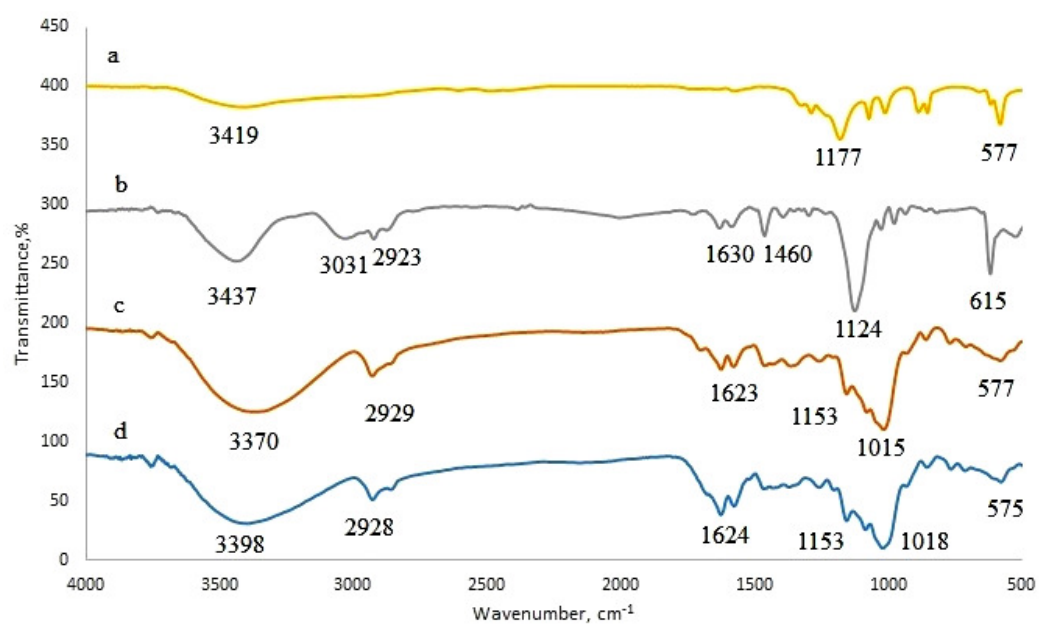

Figure 1: FTIR spectra of GO (a), GO@Amine (b), Starch@GO-Py (c) and Starch@GO-PyH.CF 3 COO nanocomposites (d) 


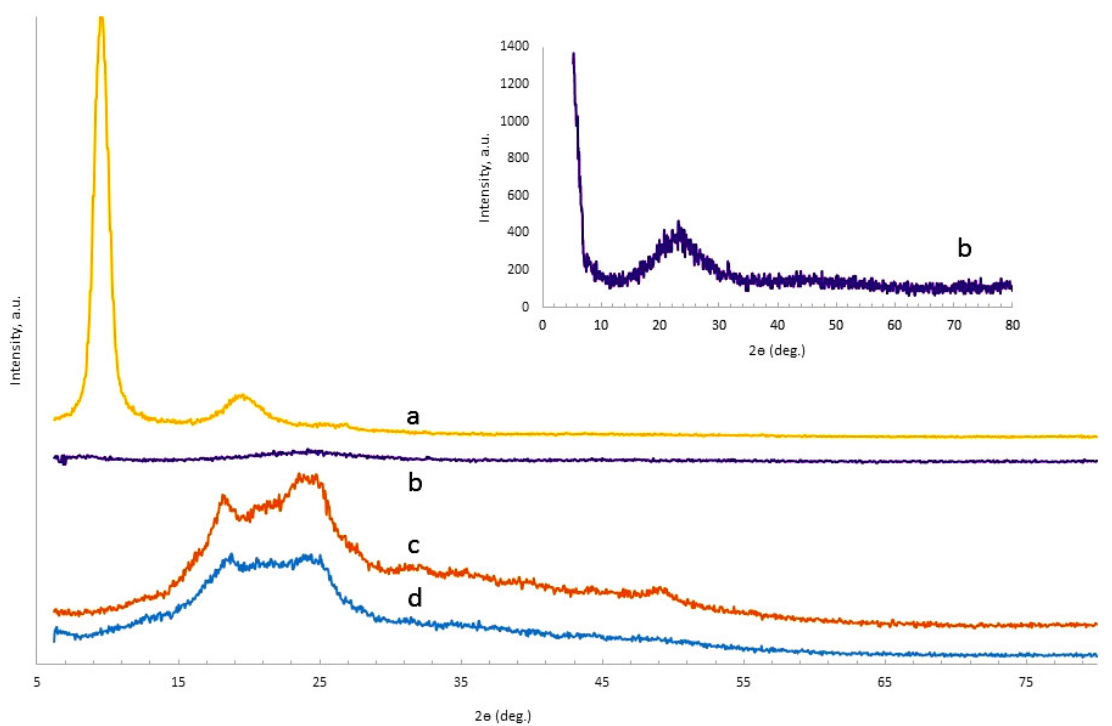

Figure 2: XRD diagrams of GO (a), GO@Amine (b), Starch@GO-Py (c) and Starch@GO-PyH.CF 3 COO nanocomposites (d)
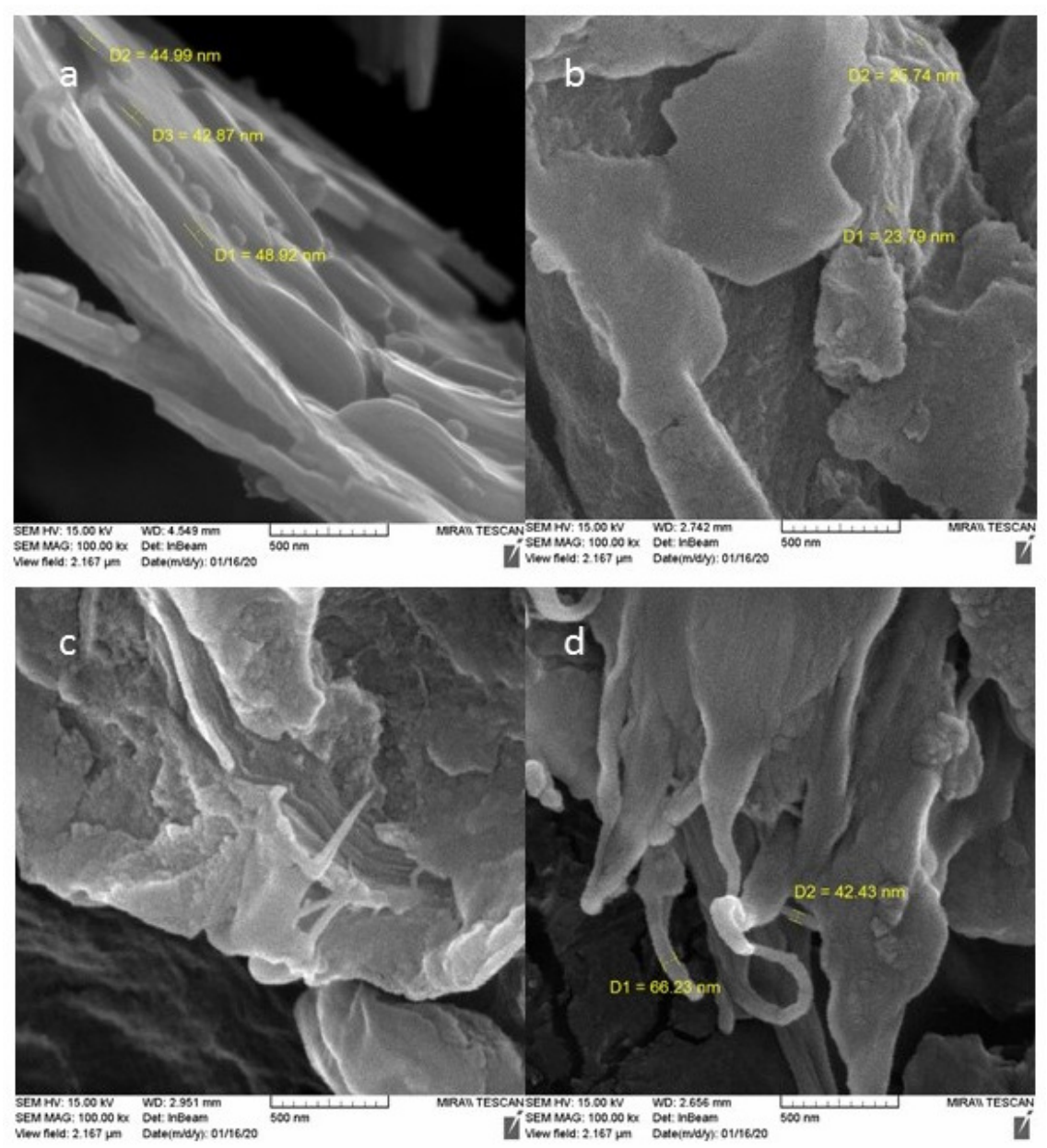

Figure 3: FESEM images of GO@Amine (a), Starch@GO-Py (b) and Starch@GO-PyH.CF ${ }_{3} \mathrm{COO}$ nanocomposites (c,d) 


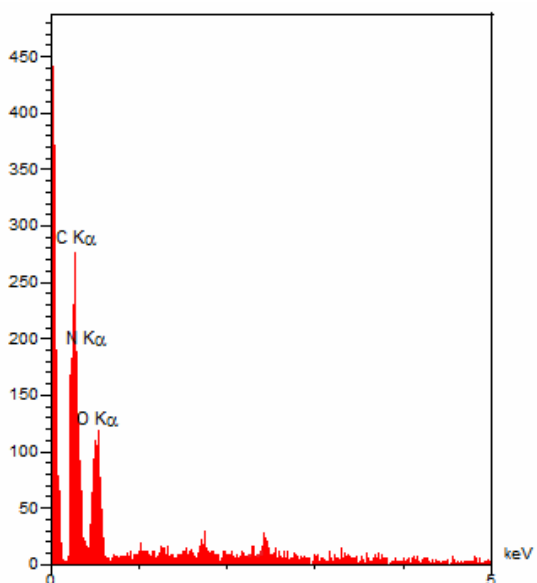

Figure 4: EDS diagram of GO@Amine
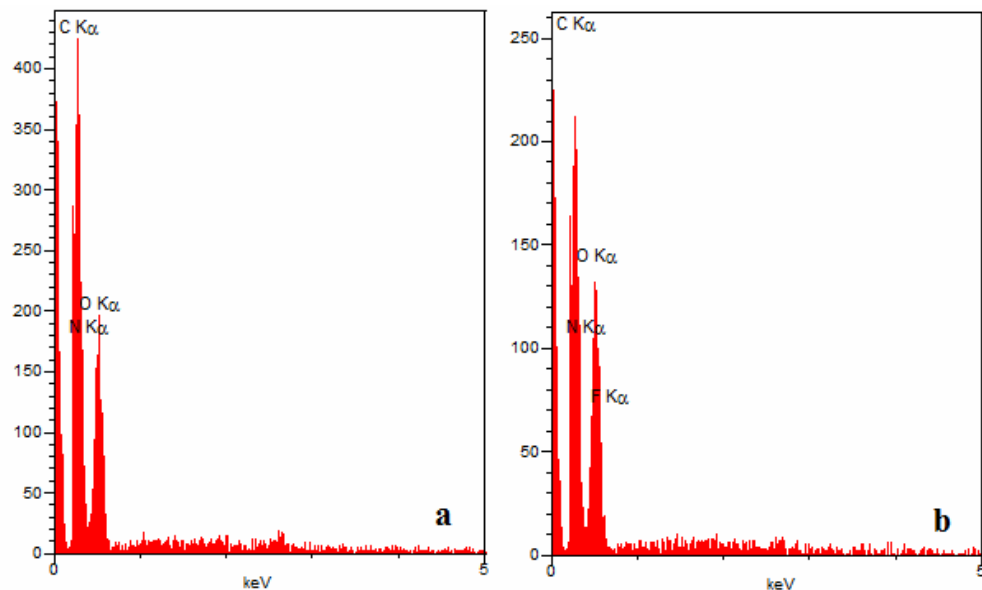

Figure 5: EDS diagrams of Starch@GO-Py (a) and Starch@GO-PyH.CF ${ }_{3} \mathrm{COO}$ (b) nanocomposites

FTIR, XRD, FESEM and EDS analyses were utilized to characterize the Starch@GO-Py composite. Figure 1c shows the FTIR spectrum of the Starch@GO-Py nanocomposite. Accordingly, $\mathrm{OH}$ and $\mathrm{NH}$ stretching vibrations can be found at $\sim 3370 \mathrm{~cm}^{-1}$. Vibrations of etheric linkages emerged at $1015-1153 \mathrm{~cm}^{-1}$. The XRD pattern of the Starch@GO-Py nanocomposite in Figure 2c also shows the structure of starch and graphene. Figure $3 b$ depicts the FESEM image of the Starch@GO-Py nanocomposite. As seen, the structure is homogeneous, indicating the strong combination of starch and graphene.

Figure 5a shows the energy dispersive spectroscopy (EDS) of the Starch@GO-Py nanocomposite, suggesting $\mathrm{C}, \mathrm{N}$, and $\mathrm{O}$ as the main elements on the surface of the sample.

To prepare the Starch@GO-PyH.CF ${ }_{3} \mathrm{COO}$ nanocomposite, trifluoroacetic acid (TFA) was added to the Starch@GO-Py nanocomposite dispersed in THF (Scheme 3). FTIR, XRD,
FESEM, EDS and TGA analyses were utilized to characterize the Starch@GO-PyH. $\mathrm{CF}_{3} \mathrm{COO}$ nanocomposite. Figure $1 \mathrm{~d}$ depicts the FTIR spectrum of the Starch@GO-PyH. $\mathrm{CF}_{3} \mathrm{COO}$ nanocomposite. As shown, $\mathrm{OH}$ and $\mathrm{NH}$ stretching vibrations are observable at $\sim 3398 \mathrm{~cm}^{-1}$. Vibrations of etheric linkages also appeared at 1018 to $1153 \mathrm{~cm}^{-1}$. The XRD pattern of the Starch@GO-PyH. $\mathrm{CF}_{3} \mathrm{COO}$ nanocomposite is presented in Figure 2d, confirming the presence of starch and graphene in the structure. Figure 3 (c and d) depicts the FESEM surface morphology of the Starch@GO-PyH.CF 3 COO nanocomposite, which indicate a homogeneous structure suggesting a strong combination of starch and graphene oxide.

According to Figure 5b, C, N, O, and F are the main elements on the surface of the Starch@GO$\mathrm{PyH} . \mathrm{CF}_{3} \mathrm{COO}$ nanocomposite.

The thermal stability of the Starch@GO$\mathrm{PyH} . \mathrm{CF}_{3} \mathrm{COO}$ nanocomposite was examined by 
thermogravimetric analysis (TGA) in the temperature range of $30-500{ }^{\circ} \mathrm{C}$, as depicted in Figure 6. Three steps of weight loss can be detected: (i) $90-130{ }^{\circ} \mathrm{C}$, (ii) $230-330{ }^{\circ} \mathrm{C}$ (main weight loss), and (iii) $375-450{ }^{\circ} \mathrm{C}$. The first weight loss probably involved the removal of the adsorbed moisture and solvents. The decomposition of the starch structure and functional groups on the surface of the Starch@GO-PyH.CF $\mathrm{COO}$ nanocomposite, including groups on the graphene oxide structure, can be assigned to the weight loss occurring at $230-330{ }^{\circ} \mathrm{C}$. The weight loss at $375-450{ }^{\circ} \mathrm{C}$ can be correlated with the decomposition of the graphene oxide structure (Fig. 6). The total weight change was of $75.37 \%$, with a char yield of $24.63 \%$. It can be concluded that the nanocomposite can be successfully applied at temperatures as high as $250{ }^{\circ} \mathrm{C}$, without significant change in its structure and functional groups.

The

Starch@GO-PyH.CF $\mathrm{COO}$ nanocomposite was employed for efficient solvent-free synthesis of 2,4,5-trisubstituted imidazoles using benzil, aldehydes, and ammonium acetate at $70{ }^{\circ} \mathrm{C}$ (Tables 1 and 2). In previous studies, in the absence of a catalyst, the reaction didn't proceed. $^{54}$ In the presence of various catalysts, including Lewis acids, however, the reaction was accomplished in an hour or less. ${ }^{14,18,21}$ Thus, in this research, a heterogeneous and environmentally benign catalyst (nanocomposite) was employed to obtain 2,4,5- trisubstituted imidazoles under green chemistry conditions in $20 \mathrm{~min}$ (Scheme 4, Table 1). The optimization of the reaction is described in Table 1. Accordingly, four variables including solvent, catalyst loading, reaction time, and temperature were optimized. The best condition was achieved when $0.02 \mathrm{~g}$ of nanocomposite was used for 20 min at $70{ }^{\circ} \mathrm{C}$ under solvent-free conditions (Table 1 , entry 12).

The efficiency and the synthesis scope of the reaction were examined under optimized conditions for a series of 2,4,5-trisubstituted imidazoles using diverse aryl aldehydes (Scheme 5 and Table 2). Table 2 reveals that the nanocomposite can be successfully used for the synthesis of various products, with excellent yields, using the substituted aldehydes under the optimized conditions through accelerated reactions and sustainable processes. According to this table, electron-withdrawing groups of aldehydes led to higher yields of trisubstituted imidazoles in shorter reaction times, as compared to electron-donating ones. The electronwithdrawing groups induced a positive charge to the carbon atom in the carbonyl group of aldehyde and accelerated the nucleophilic attack of ammonia on the aldehyde. On the other hand, electron-withdrawing groups accelerated the removal of water from the intermediates in the presence of nanocomposite and the formation of imidazole.

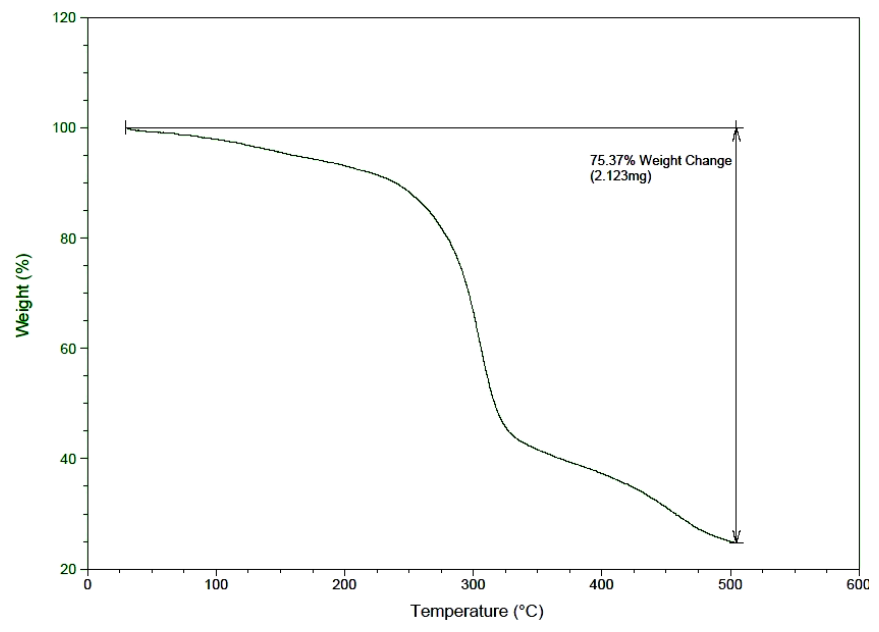

Figure 6: Thermogravimetric (TG) analysis of Starch@GO-PyH. $\mathrm{CF}_{3} \mathrm{COO}$ nanocomposite 
Table 1

Effect of nanocomposite (Starch@GO-PyH.CF $3 \mathrm{COO}$ ) loading, temperature, time and solvent on the model reaction

\begin{tabular}{cccccc}
\hline Entry & Solvent & $\begin{array}{c}\text { Catalyst } \\
(\mathrm{g})\end{array}$ & $\begin{array}{c}\text { Temperature } \\
\left({ }^{\circ} \mathrm{C}\right)\end{array}$ & $\begin{array}{c}\text { Time } \\
(\mathrm{min})\end{array}$ & $\begin{array}{c}\text { Yield }^{\mathrm{a}} \\
(\%)\end{array}$ \\
\hline 1 & EtOH & - & Reflux & 60 & trace \\
2 & EtOH & 0.01 & Reflux & 60 & 80 \\
3 & EtOH & 0.02 & Reflux & 60 & 90 \\
4 & $\mathrm{CH}_{3} \mathrm{CN}$ & 0.02 & Reflux & 60 & 82 \\
5 & $\mathrm{CHCl}_{3}$ & 0.02 & Reflux & 60 & 75 \\
6 & $\mathrm{MeOH}$ & 0.02 & Reflux & 60 & 83 \\
7 & Water & 0.02 & 90 & 60 & 51 \\
8 & DMSO & 0.02 & 100 & 60 & 56 \\
9 & DMF & 0.02 & 100 & 60 & 62 \\
10 & Solvent-free & 0.01 & 70 & 20 & 88 \\
11 & Solvent-free & 0.01 & 80 & 20 & 91 \\
12 & Solvent-free & 0.02 & 70 & 20 & 95 \\
13 & Solvent-free & 0.02 & 80 & 10 & 91 \\
14 & Solvent-free & 0.02 & 90 & 5 & 75 \\
15 & Solvent-free & 0.03 & 70 & 20 & 95 \\
\hline
\end{tabular}

a Isolated yield

Table 2

Synthesis of 2,4,5-trisubstituted imidazoles catalyzed by Starch@GO-PyH.CF ${ }_{3} \mathrm{COO}$ nanocomposite

\begin{tabular}{ccccccc}
\hline \multirow{2}{*}{ Entry } & \multirow{2}{*}{$\mathrm{R}$} & \multirow{2}{*}{ Product } & \multirow{2}{*}{$\begin{array}{c}\text { Time } \\
(\mathrm{min})\end{array}$} & $\begin{array}{c}\text { Yield } \\
(\%)^{\mathrm{a}}\end{array}$ & & \multicolumn{2}{c}{$\mathrm{mp} /{ }^{\circ} \mathrm{C}$} \\
\hline 1 & $\mathrm{H}$ & $\mathbf{3 a}$ & 20 & 95 & $276-277$ & $274-276^{55}$ \\
2 & $4-\mathrm{Me}$ & $\mathbf{3 b}$ & 25 & 92 & $231-232$ & $230-232^{55}$ \\
3 & $4-\mathrm{MeO}$ & $\mathbf{3 c}$ & 25 & 91 & $228-229$ & $229-231^{55}$ \\
4 & $4-\left(\mathrm{CH}_{3}\right)_{2} \mathrm{~N}$ & $\mathbf{3 d}$ & 30 & 87 & $257-258$ & $257-259^{55}$ \\
5 & $4-\mathrm{F}$ & $\mathbf{3 e}$ & 15 & 96 & $252-253$ & $253-254^{56}$ \\
6 & $4-\mathrm{Cl}$ & $\mathbf{3 f}$ & 15 & 96 & $261-262$ & $262-264^{55}$ \\
7 & $2,4-\mathrm{diCl}$ & $\mathbf{3 g}$ & 15 & 90 & $169-170$ & $168-170^{54}$ \\
8 & $4-\mathrm{OH}$ & $\mathbf{3 h}$ & 25 & 89 & $268-269$ & $268-270^{55}$ \\
9 & $2-\mathrm{Cl}$ & $\mathbf{3 i}$ & 15 & 90 & $192-193$ & $190-192^{55}$ \\
10 & $3-\mathrm{O}_{2} \mathrm{~N}$ & $\mathbf{3 j}$ & 15 & 97 & $314-315$ & $315-317^{55}$ \\
11 & $4-\mathrm{O}_{2} \mathrm{~N}$ & $\mathbf{3 k}$ & 15 & 96 & $242-243$ & $202-203^{56}$ \\
12 & $4-\mathrm{NO}_{2}-\mathrm{Ph}-\mathrm{CH} \mathrm{O}_{2} \mathrm{O}^{57}$ & $\mathbf{3 l}$ & 30 & 87 & $215-216$ & - \\
\hline
\end{tabular}

\section{${ }^{\mathrm{a}}$ Isolated yield}

${ }^{1} \mathrm{H}$ NMR and ${ }^{13} \mathrm{C}$ NMR spectroscopies were employed to assess the structure of $3 \mathrm{a} .{ }^{1} \mathrm{H}$ NMR results indicated 13 aromatic protons in the range of 7.29-7.63 ppm as a multiplet. Two aromatic protons were detected as a multiplet in the range of 8.17-8.20 ppm. One $\mathrm{NH}$ proton can be observed at $13.13 \mathrm{ppm}$ as a singlet. Thus, the number of protons in the ${ }^{1} \mathrm{H}$ NMR spectrum confirmed the structure. The ${ }^{13} \mathrm{C}$ NMR spectrum exhibited 11 carbons, including aliphatic and aromatic ones. Thus, ${ }^{13} \mathrm{C}$ NMR confirmed the number of carbon atoms. Hence, NMR spectra verified the structure of $\mathbf{3 a}$.

${ }^{1} \mathrm{H}$ NMR and ${ }^{13} \mathrm{C}$ NMR spectroscopies were also employed to determine the structure of $\mathbf{3 j}$. ${ }^{1} \mathrm{H}$
NMR results indicated six aromatic protons as a multiplet in the range of 7.31-7.43 ppm. Four aromatic protons as a multiplet were observed in the range of 7.56-7.58 ppm. One aromatic proton was also found in 7.73-7.78 ppm as a multiplet. One aromatic proton as doublet with a coupling constant $(J)$ of $8.2 \mathrm{~Hz}$ also appeared at $8.2 \mathrm{ppm}$. Moreover, one aromatic proton can be seen as a doublet in $8.53 \mathrm{ppm}$ with $J=7.9 \mathrm{~Hz}$. One NH proton is detected as a singlet in $8.98 \mathrm{ppm}$. Thus, the number of protons in the ${ }^{1} \mathrm{H}$ NMR spectrum confirmed the structure. The ${ }^{13} \mathrm{C}$ NMR spectrum indicated 13 carbons and confirmed the number of carbon atoms, hence, NMR spectra verified the structure of $\mathbf{3 j}$. 
${ }^{1} \mathrm{H}$ NMR and ${ }^{13} \mathrm{C}$ NMR spectroscopies were employed to evaluate the structure of $\mathbf{3 l}$. ${ }^{1} \mathrm{H}$ NMR results indicated two methylene protons in 5.35 ppm as a singlet. Two aromatic protons were also detected as a multiplet in the range of 7.14-7.16 $\mathrm{ppm}$. Ten aromatic protons were seen at 7.30-7.51 ppm as a multiplet. Moreover, one proton can be found at $7.76 \mathrm{ppm}$ as a triplet with $J=3.0 \mathrm{~Hz}$. Two protons were detected as a multiplet in the range of 8.02-8.04 ppm and two protons were also observed at 8.27-8.29 ppm as a multiplet. One proton can be observed in $12.53 \mathrm{ppm}$ as a singlet. Thus, the number of protons in the ${ }^{1} \mathrm{H}$ NMR spectrum confirmed the structure. ${ }^{13} \mathrm{C}$ NMR confirmed the number of carbon atoms in the structure. Hence, NMR spectra verified the structure of 31. Additionally, mass analysis confirmed the synthesis of $\mathbf{3 1}$.

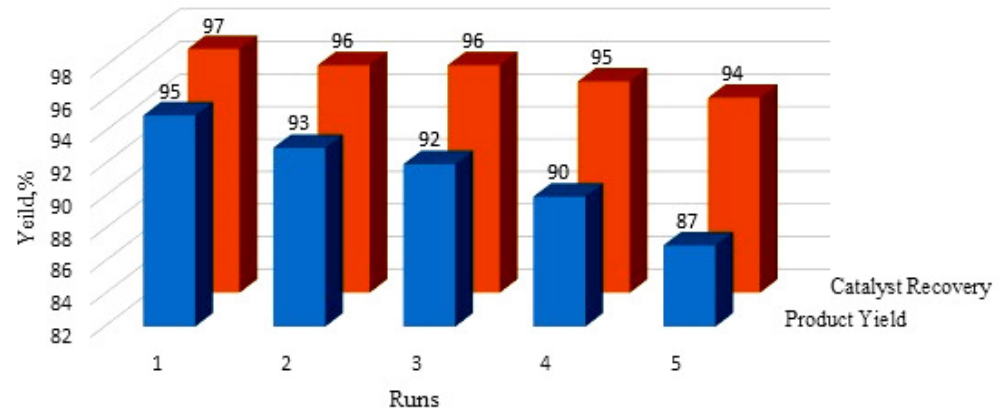

Figure 7: Product yield of 3a and Starch@GO-PyH- $\mathrm{CF}_{3} \mathrm{COO}$ nanocomposite recovery and reusability for five runs

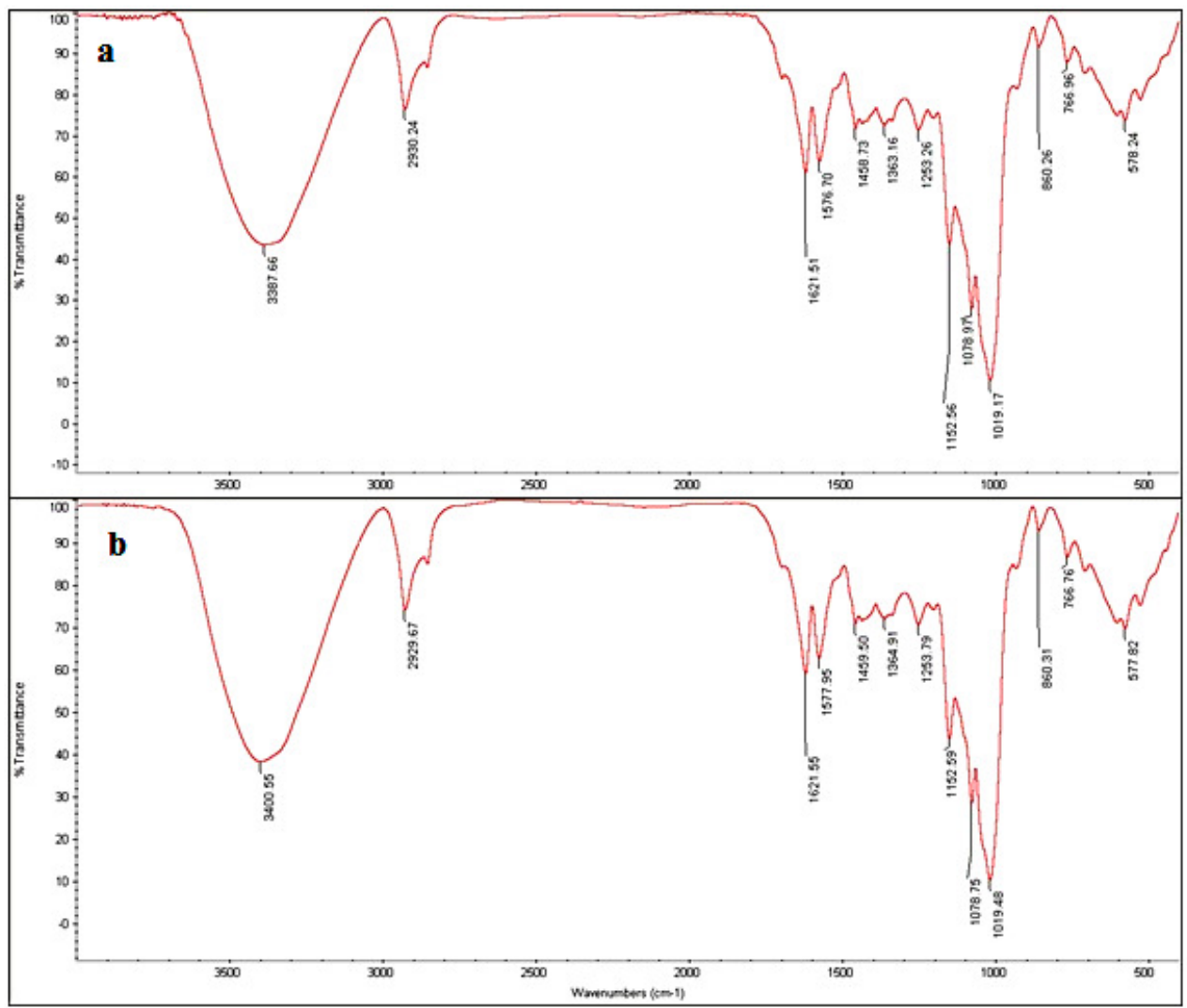

Figure 8: FTIR spectra of Starch@GO-PyH- $\mathrm{CF}_{3} \mathrm{COO}$ nanocomposite, (a) after two years of storage and (b) after 5 cycles of usage 
The reusability and durability of the nanocomposite (catalyst) was evaluated by its recovery and reuse in the reaction (product 3a). According to the results (Fig. 7), no significant change was observed in the recovery of the nanocomposite and product yield after five successive runs. Moreover, FTIR and FESEM results of the nanocomposite (Figs. 8 and 9) after two years of storage at room temperature were compared with those recorded after five runs.

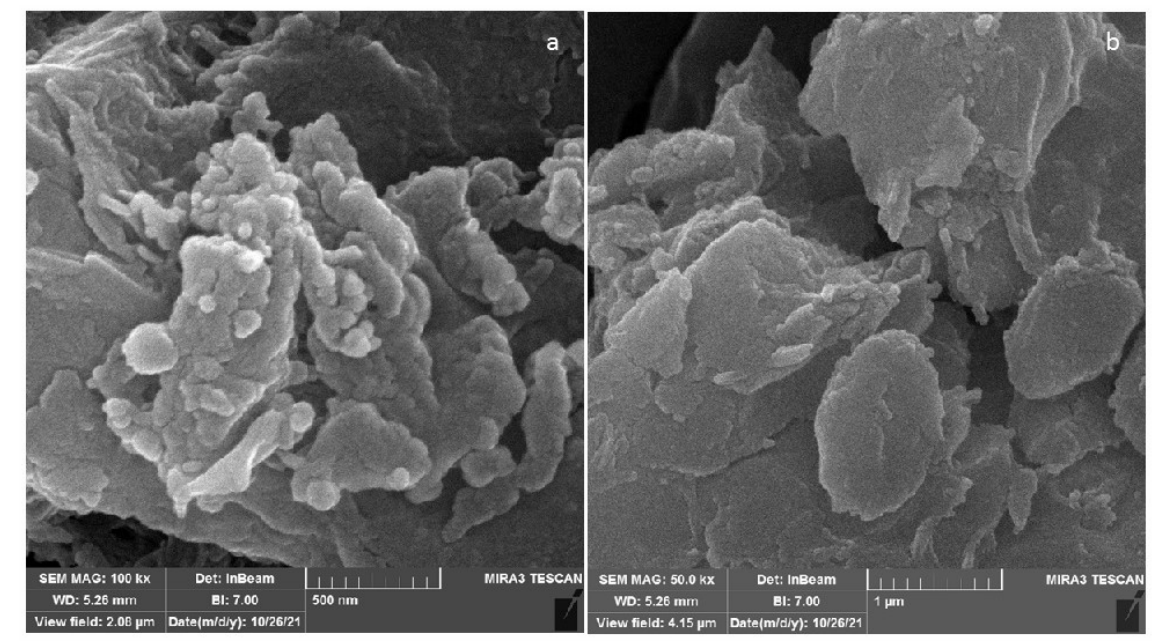

Figure 9: FESEM images of Starch@GO-PyH- $\mathrm{CF}_{3} \mathrm{COO}$ nanocomposite, (a) after two years of storage and (b) after five cycles of usage

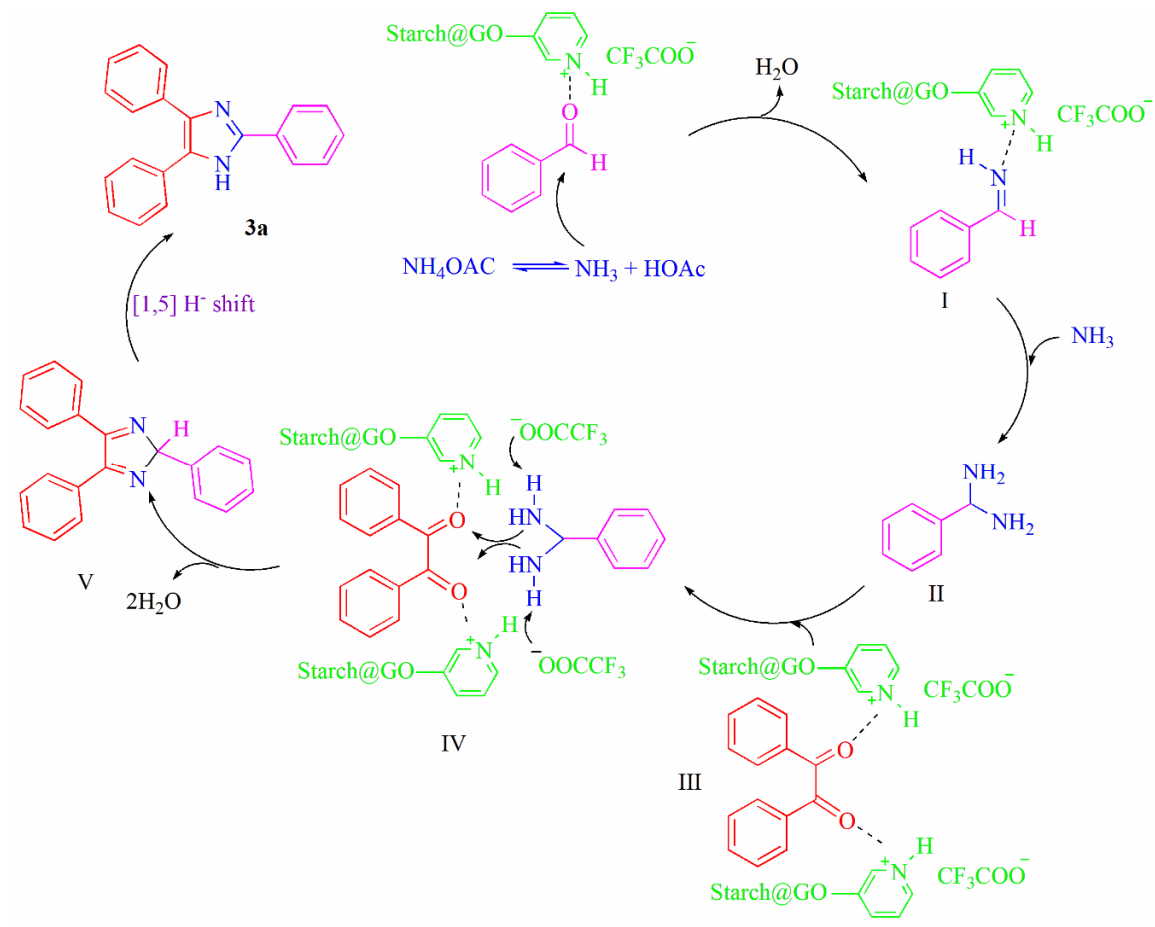

Scheme 6: Plausible mechanism for the synthesis of $\mathbf{3 a}$

Accordingly, no significant difference can be observed between the FTIR spectra in Figure 8 with those in Figure 1d. A comparison of FESEM images in Figure 9 and Figure 3 (c and d) also revealed no significant difference. These observations confirmed the stability of the 
nanocomposite within two years of storage and after 5 successive runs.

\section{Mechanism of the reaction}

The proposed mechanism of the synthesis of trisubstituted imidazoles through the Starch@GO$\mathrm{PyH}-\mathrm{CF}_{3} \mathrm{COO}$ nanocomposite is depicted in Scheme 6 . First, the aldehyde carbonyl group was activated by the nanocomposite, which resulted in imine intermediate (I) by the attack of ammonia and subsequent removal of water. Then, another ammonia molecule attacked the imine intermediate (I) to yield II. In the next step, activated benzil (III) and II were reacted through IV to afford intermediate V. Finally, [1,5] hydride shifted on $\mathbf{V}$, which led to the formation of trisubstituted imidazole (3a).

\section{CONCLUSION}

Graphene oxide was successfully functionalized by 1,8-diamino-3,5-dioxaoctane under appropriate conditions. Starch/functionalized graphene oxide/3aminopyridine, nanocomposite was efficiently prepared by hexamethylene diisocyanate (HDMI) as a binding agent. In the next step, the trifluoroacetic acid-supported nanocomposite was successfully obtained. The starch/graphene oxidebased nanocomposite (catalyst) has some advantages, including cost-effectiveness, green chemistry properties, the use of natural and nontoxic precursors, thermal stability, reusability, durability and ease of handling and storage. 2,4,5trisubstituted imidazoles were efficiently prepared through a solvent-free synthetic route, using benzil, aryl aldehydes, ammonium acetate and nanocomposite in a short reaction time. The process successfully achieved some proposed priorities, including moderate and accelerated reaction conditions, efficient purification process, solvent-free condition and sustainability. Thus, this research proposes a novel nanocomposite based on starch and graphene oxide, with superior properties, capable of accelerating organic reactions.

ACKNOWLEDGMENT: The authors would like to express their gratitude to the Payame Noor University (PNU) Research Council for supporting this research study.

\section{REFERENCES}

1 V. Kumar, K. Kaur, G. K. Gupta and A. K. Sharma, Eur. J. Med. Chem., 69, 735 (2013), https://doi.org/10.1016/j.ejmech.2013.08.053
2 M. Thwin, B. Mahmoudi, O. A. Ivaschuk and Q. A. Yousif, $\quad R S C \quad A d v$., 9, $15966 \quad$ (2019), https://doi.org/10.1039/C9RA02325A

A. A. Marzouk, A. K. Bass, M. S. Ahmed, A. A. Abdelhamid, Y. A. Elshaier et al., Bioorg. Chem., 101, 104020

(2020), https://doi.org/10.1016/j.bioorg.2020.104020

4 M. Hossain and A. K. Nanda, Science, 6, 83 (2018), https://doi.org/10.11648/j.sjc.20180605.12

5 S. Ohnmacht, P. Nava, R. West, R. Parker and J. Atkinson, Bioorg. Med. Chem., 16, 7631 (2008), https://doi.org/10.1016/j.bmc.2008.07.020

6 M. Bastide, S. Jouvert and J. M. Bastid, Can. J. Microbiol., $\quad 28, \quad 1119$ https://doi.org/10.1007/s42452-019-0935-0

7 T. Maier, R. Schmierer, K. Bauer, H. Bieringer, H. Buerstell et al., U. S. Patent 4820 335, (1989), Chem. Abstr., 111, 19494w (1989), https://patft.uspto.gov

8 R. Schmierer, H. Mildenberger and H. Buerstell, German Patent 361464, (1987), Chem. Abstr., 108, 37838 (1988), https://ep.espacenet.com

9 V. G. Silva, R. O. Silva, S. R. Damasceno, N. S. Carvalho, R. S. Prudêncio et al., J. Nat. Prod., 76, 1071 (2013), https://doi.org//10.1021/np400099m

10 S. L. Abrahams, R. J. Hazen, A. G. Batson, A. P. Phillips, J. Pharm. Exp. Therap., 249, 359 (1989), https://citeseerx.ist.psu.edu

${ }_{11}$ M. Masteri-Farahani, A. Ezabadi, R. Mazarei, P. Ataeinia, S. Shahsavarifar et al., Appl. Organomet. Chem., 34, 35727 https://doi.org/10.1002/aoc.5727

12 S. Naeim-Fallahiyeh, E. Rostami, H. Golchaman and S. Kaman-Torki, Res. Chem. Intermed., 46, 4141 (2020), https://doi.org/10.1007/s11164-020-04197-6

13 P. S. G. Nunes, H. D. A. Vidal and A. G. Corrêa, Org. Biomol. Chem., 18, 7751 (2020), https://doi.org/10.1039/D0OB01631D

14 S. Pervaiz, S. Mutahir, I. Ullah, M. Ashraf, X. Liu et al., Chem. Biodivers., 17, e1900493 (2020), https://doi.org/10.1002/cbdv.201900493

15 M. Masteri-Farahani, A. Ezabadi, R. Mazarei, P. Ataeinia, S. Shahsavarifar et al., Appl. Organomet. Chem., 34, e5727 (2020), https://doi.org/10.1002/aoc.5727

16 B. Karami, K. Eskandari and A. Ghasemi, Turk. J. Chem., 36, 601 (2012), https://doi.org/10.3906/kim1112-49

17 J. Safari, Z. Akbari and S. Naseh, J. Saudi Chem. Soc., 20, S250 https://doi.org/10.1016/j.jscs.2012.10.012

${ }_{18}$ M. M. Heravi, K. Bakhtiari, H. A. Oskooie and S. Taheri, J. Mol. Cat. A, 263, 279 (2007), https://doi.org/10.1016/j.molcata.2006.08.070

19 V. D. Patil, N. R. Sutar, K. P. Patil and P. Giddh, Der Chem. Sin., 7, $23 \quad$ (2016), www.pelagiaresearchlibrary.com

20 M. Nasr-Esfahani, M. Montazerozohori and T. Abdizadeh, Chem. Pap., 69, 1491 (2015), https://doi.org/10.1515/chempap-2015-0156 
21 G. V. M. Sharma, Y. Jyothi and P. S. Lakshimi, Synth. Commun., 36, $2991 \quad$ (2006), https://doi.org/10.1080/00397910600773825

22 J. Tan, J. R. Li and Y. L. Hu, J. Saudi Chem. Soc., 24, $777 \quad$ (2020), https://doi.org/10.1016/j.jscs.2020.08.006

23 L. Z. Fekri, M. Nikpassand, S. Shariati, B. Aghazadeh and R. Zarkeshvari, J. Organomet. Chem., 871, 60 (2018), https://doi.org/10.1016/j.jorganchem.2018.07.008

24 J. N. Sangshetti, N. D. Kokare, S. A. Kotharkara and D. B. Shinde, J. Chem. Sci., 120, 463 (2008), https://doi.org/10.1007/s12039-008-0072-6

25 C. Samorì, A. Parodi, E. Tagliavini and P. Galletti, J. Anal. Appl. Pyrol., 155, 105030 (2021), https://doi.org/10.1016/j.jaap.2021.105030

26 M. Nasrollahzadeh, M. Sajjadi, M. Shokouhimehr and R. S. Varma, Coord. Chem. Rev., 397, 54 (2019), https://doi.org/10.1016/j.ccr.2019.06.010

27 Q. Huang, J. Chen, M. Liu, H. Huang, X. Zhang et al., Chem. Eng. J., 387, 124019 (2020), https://doi.org/10.1016/j.cej.2020.124019

28 I. Boulhaia, N. Moulai-Mostefa, A. Hadjsadok and A. Aouabed, Cellulose Chem. Technol., 54, 545 (2020),

https://doi.org/10.35812/CelluloseChemTechnol.2020. 54.55

${ }_{29}$ M. Hong, J. Min, S. Wu, J. Li, J. Wang et al., Appl. Organomet. Chem., 34, e5411 (2020), https://doi.org/10.1002/aoc.5411

30 N. S. Sulaiman, R. Hashim, S. Hiziroglu, M. H. M. Amini, O. Sulaiman et al., Cellulose Chem. Technol., 50, 329 (2016)

https://www.cellulosechemtechnol.ro/pdf/CCT2(2016) /p.329-338.pdf

31 M. Tukhani, F. Panahi and A. Khalafi-Nezhad, ACS Sustain. Chem. Eng., 6, 1456 (2018), https://doi.org/10.1021/acssuschemeng.7b03923

32 C. W. Chiu and D. Solarek, in "Starch" edited by J. BeMiller and R. Whistler, Academic Press, 2009, pp. 629-655, https://doi.org/10.1016/B978-0-12-7462752.00017-3

33 Đ. Ačkar, J. Babić, A. Jozinović, B. Miličević, S. Jokić et al., Molecules, 20, 19554 (2015), https://doi.org/10.3390/molecules201019554

34 S. X. Xie, Q. Liu and S. W. Cui, "Starch Modification and Applications", CRC Press, Boca Raton, FL, 2005, p. 357, https://doi.org/10.1201/9780203485286.ch8

35 M. Holban, V. Sunel, M. Popa and C. Lionte, Cellulose Chem. Technol., 45, 191 (2011), https://www.cellulosechemtechnol.ro/pdf/CCT34(2011)/p.191-196.pdf

36 N. E. Kochkina and N. D. Lukin, Cellulose Chem. Technol., $\quad 53, \quad 133 \quad$ (2019), https://doi.org/10.35812/CelluloseChemTechnol.2019. 53.15
37 M. Arghan, N. Koukabi and E. Kolvari, Appl. Organomet. Chem., 33, e5075 (2019), https://doi.org/10.1002/aoc.5075

38 M. Kumar, H. S. Dosanjh, J. Singh, K. Monir and H. Singh, Environ. Sci. Water Res. Technol., 6, 491 (2020), https://doi.org/10.1039/C9EW00858F

39 I. M. Abdelmonem, E. Metwally, T. E. Siyam, F. A. El-Nour and A. R. M. Mousa, J. Radioanal. Nucl. Chem., 319, 1145 (2019), https://doi.org/10.1007/s10967-018-6392-1

40 S. Sethi, B. S. Kaur, M. Kaith, N. Sharma and S. Khullar, J. Biomater. Sci. Polym. Ed., 30, 1687 (2019), https://doi.org/10.1080/09205063.2019.1659710

41 C. W. Zhang, S. S. Nair, H. Chen, N. Yan, R. Farnood et al., Carbohyd. Polym., 230, 115626 (2020), https://doi.org/10.1016/j.carbpol.2019.115626

${ }^{42}$ K. B. Narayanan, H. D. Kim and S. S. Han, Colloids Surf. B Biointerface, 185, 110579 (2020), https://doi.org/10.1016/j.colsurfb.2019.110579

43 Z. Wang, X. Zhang, X. Wu, J. G. Yu, X. Y. Jiang et al., Sol-Gel Sci. Techn., 82, 440 (2017), https://doi.org/10.1007/s10971-017-4313-3

44 K. González, C. García-Astrain, A. SantamariaEchart, L. Ugarte, L. Avérous et al., Carbohyd. Polym., 202, $372 \quad$ (2018), https://doi.org/10.1016/j.carbpol.2018.09.007

45 M. Aqlil, A. M. Nzenguet, Y. Essamlali, A. Snik, M. Larzek et al., J. Agric. Food Chem., 65, 10571 (2017), https://doi.org/10.1021/acs.jafc.7b04155

46 F. Mohanty and S. K. Swain, Nano-Struc. NanoObjects, $\quad \mathbf{1 8}, \quad 100300 \quad$ (2019), https://doi.org/10.1016/j.nanoso.2019.100300

47 J. P. Ambre, K. B. Dhopte, P. R. Nemade and V. H. Dalvi, J. Environ. Chem. Eng., 7, 103300 (2019), https://doi.org/10.1016/j.jece.2019.103300

${ }^{48}$ W. Wu, Y. Li, L. Yang, Y. Ma, D. Pan et al., Electrochim. Acta, 139, $117 \quad$ (2014), https://doi.org/10.1016/j.electacta.2014.06.166

49 P. P. Peregrino, M. J. Sales, M. F. da Silva, M. A. Soler, L. F. da Silva et al., Carbohyd. Polym., 106, 305 (2014), https://doi.org/10.1016/j.carbpol.2014.02.008

50 P. Wang, S. Tang, F. Sheng, J. Cai, P. Fei et al., Int. J. Biol. Macromol., 132, 1208 (2019), https://doi.org/10.1016/j.ijbiomac.2019.03.183

51 E. Yarahmadi, K. Didehban, M. G. Sari, M. R. Saeb, M. Shabanian et al., Prog. Org. Coat., 119, 194 (2018), https://doi.org/10.1016/j.porgcoat.2018.03.001 52 W. S. Hummers Jr. and R. E. Offeman, J. Am. Chem. Soc., 80, 1339 (1958), http://dx.doi.org/10.1021/ja01539a017

53 R. Muzyka, M. Kwoka, Ł. Smędowski, N. Díez and G. Gryglewicz, New Carbon Mater., 32, 15 (2017), https://doi.org/10.1016/S1872-5805(17)60102-

54 R. Khalifeh, V. Naseri and M. Rajabzadeh, ChemistrySelect, $\quad 5, \quad 11453 \quad$ (2020), https://doi.org/10.1002/slct.202003133 


\section{ESMAEL ROSTAMI and MARYAM SADAT GHORAYSHI NEJAD}

55 E. Eidi, M. Z. Kassaee and Z. Nasresfahani, Appl. Organomet. Chem., 30, $561 \quad$ (2016), https://doi.org/10.1002/aoc.3470
56 T. T. Nguyen, N. P. T. Le and P. H. Tran, $R S C$ Adv., $\quad$ 9, $38148 \quad$ (2019), https://doi.org/10.1039/C9RA08074K

57 E. Rostami and S. H. Zare, ChemistrySelect, 4, 13295 (2019), https://doi.org/10.1002/slct.201902864 